\title{
Sensory and Comparative Analysis of Ordinary Garri and Cocosgarri (Nutritionally enriched)
}

\author{
Chinwe, O. U., Ozumba. I. C., Adejumo,O. A., Ayuba O.L., Nwosu Caeser., \\ Bosa, S.O., Idowu, O \\ Agro-Industrial Development and Extension Department \\ National Centre for Agricultural Mechanization \\ P.M.B. 1525, Ilorin, Kwara State, Nigeria
}

\begin{abstract}
The paper deals with the production of CocosGarri, its sensory evaluation and comparative analysis with ordinary Garri. Garri made from cassava was fortified in order to improve its nutritional value using improved technology. Fortification was done using Coconut milk, milk, sugar and vanilla food flavour. Results showed that there was a significant difference between CocosGarri and ordinary garri in terms of crispiness, flavour/taste, sweetness, mouth feel and aroma. However, there was no significant difference between the appearance of the CocosGarri and ordinary garri, though Cocosgarri was still preferred due to its finer particle size. This speaks of the overall acceptability of CocosGarri over ordinary garri and therefore can be recommended to people of all age group because of its delicious taste and high nutritional value.
\end{abstract}

Keywords: Ordinary garri, CocosGarri, Coconut milk, Sensory evaluation, nutritional value, acceptability.

\section{INTRODUCTION}

A staple food, sometimes simply referred to as a staple, is a food that is eaten routinely, and in such quantities that it constitutes a dominant portion of a standard diet in a given people, supplying a large fraction of the needs for energy rich materials and generally a significant proportion of the intake of other nutrients as well (FA0, 2010).

Cassava is one of the most important staple food crops grown in tropical Africa and Nigeria is the current leading cassava producing country in the world (Oyewole, 1991). It plays a major role in efforts to alleviate the African food crisis because of its efficient production of food energy, yearround availability, tolerance to extreme stress conditions, and suitability to present farming and food systems in Africa (Hahn and Keyser, 1985 \& Hahn et al. 1987). According to the Food and Agriculture Organization of the United Nations Global Cassava Development Strategy, cassava is the third most important source of calories in the tropics, after rice and corn. Millions of people depend on cassava in Africa, Asia and Latin America. It is grown by poor farmers, many of them women, often on marginal land. This crop is vital for both food security and income generation (FAO, 2004).

Traditionally, cassava roots are processed by various methods into numerous products and utilized in various ways according to local customs and preferences. One of the processed products of Cassava is Garri. It is widely eaten in the West and Central Africa and forms a staple food for majority of the people in the southern part of Nigeria. An estimate of about ten million tonnes is produced in Nigeria alone per annum (Okafor, 1992). Sometimes these staple foods like garri can lack particular nutrients, therefore the need to fortify or enrich it. Due to the inherent inadequacy of the normal diet, addition of nutrient to staple foods can prevent large-scale deficiency diseases and malnutrition which could result from consuming the staple foods alone (WHO and FAO, 2006).

CocosGarri is a nutritionally enriched drinking garri which is rich in protein, minerals and vitamins and other essential nutrients needed for the body growth and metabolism. It is enriched with Coconut milk, condensed milk and sugar and vanilla flavour to improve its nutritional quality and taste thereby making it very healthy and palatable for consumption. This meal can serve as a snack and a regular meal as it is commonly taken by some people. Therefore using improved technology to produce CocosGarri was carried out to enrich the nutritional value of ordinary garri. The research was achieved by sensory evaluation of consumers' preference in comparison with regular drinking garri. 


\section{Objectives}

This research work is based on;

- The need to enrich the regular drinking garri thereby making it tastier, delicious and more nutritious for consumption and to determine consumers' preference in comparison with regular drinking garri.

- To carry out sensory evaluation of CocosGarri in comparison with the regular drinking garri.

- To evaluate these compositions using sensory evaluation techniques.

\section{MATERIALS AND MeThODS}

The study was carried out at the Food Laboratory of the National Centre for Agricultural Mechanization, Ilorin, Kwara State, Nigeria (Longitude $4^{0}, 30^{1}$ East and Latitude $8^{0}, 26^{1}$ North). The production of CocosGarri involves a process of mixing the coconut milk, condensed milk, sugar and vanilla food flavour into already prepared garri to form a homogenous mixture, allowing the mixture to stand for two hours and heat drying for five minutes. Sensory evaluation and nutrient analysis were carried out on CocosGarri immediately after production and after stored for a period of six months in order to ascertain if there were any changes in its taste, aroma, flavor, colour and crispiness. The results obtained were subjected to statistical analysis using Excel 2013. The production process can be seen as shown in Fig 1.

\section{Fresh Cassava Tubers}

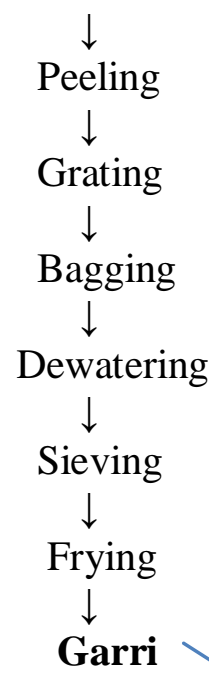

\section{Fresh Coconut meat}<smiles>[AlH2]I</smiles><smiles>[131InH2]</smiles><smiles>[AlH2]</smiles><smiles>[GeH3][Hg]</smiles><smiles>[AlH2]</smiles>

Steeping with hot water<smiles>[AlH2]</smiles>

Blending<smiles>[AlH2]</smiles>

Extracting the Liquid

Fresh Coconut milk

Addition of condensed milk, sugar, vanilla flavor

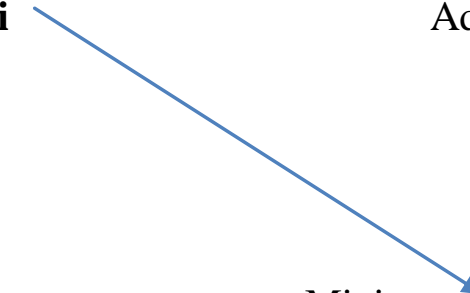

Mixing with Garri for 2hours

Pasteurizing (45mins) and cooling

Frying for 5minutes

\section{COCOSGARRI}

Fig 1. Flow Chart showing the production process of CocosGarri

\subsection{Raw Materials}

Fresh Cassava tubers (Manihot esculenta) were obtained from the NCAM Research Farm. Coconut (Cocos nucifera), condensed milk, sugar and vanilla flavor were bought from a nearby market.

\subsection{Production Procedure}

Preparation of garri from Cassava roots was done according to the method described by (Hahn, 1989 and Odunfa, 1998). Fresh Cassava roots were peeled manually using a knife (as practiced traditionally) washed and grated to produce a mash. The grated product was then put into a jute sack 
and the sack tied. The mash filled sacks were stacked up on each other and a wooden board placed below and above the sacks. (This step is to ensure fermentation takes place which will help to reduce and detoxify the high cyanide content of cassava). Tension was created by tightening the rope and pressing the wooden board, thus allowing water to run out of the grated cassava. The dewatered and fermented lumps of pulp were crumbled by hand and most of the fibrous matter was removed .The dried cassava mash was then sieved and roasted in an earthen pot over a fire till a dullish white colour was obtained. $40 \mathrm{~kg}$ of freshly made garri was neatly weighed into two portions into a bowl using a weighing balance, one which will be used as a control sample (Ordinary garri) and the other which will be enriched with coconut milk, milk, sugar and vanilla food flavor (CocosGarri). The Coconut was cracked and dehusked to get the coconut meat. The Coconut meat was finely grated into a bowl and hot water was added to it. The coconut meat and water were mixed together and allowed to soak for one hour. The mixture was blended using a Kenwood blender to form a slurry and the liquid strained using a muslin cloth. The coconut milk obtained was mixed with the condensed milk, sugar and the vanilla flavor to form a homogeneous mixture. The mixture was pasteurized for 45 minutes using the batch method of pasteurization as described by Lewis et al, 2000, covered and left for a period of 12 hours. The mixture was added into the neatly fried garri and allowed to sit for 2 hours so that the garri can soak in the milk. The mixture was then re-fried for 5 minutes to give CocosGarri. The production process can be seen in Fig I.

\subsection{Sensory Evaluation}

A 10 member panel who are regular garri consumers with experience in sensory evaluation was selected and briefed. CocosGarri was tested $24 \mathrm{~h}$ after production and presented to the panelists. This was done by mixing CocosGrarri in a small bowl with water and ordinary garri in a separate bowl with water without the addition of sugar or milk. The parameters evaluated were colour, appearance, crispiness, flavour and taste, sweetness, aroma, mouth feel and its overall acceptability. The panelists were asked to indicate their observations using a six point hedonic scale of parameters ranging from 1 (dislike extremely) to 7 (like extremely). The procedure and analysis of the results were carried out following standard methods (ISO 6564- 1985).

\section{RESULTS AND DisCUSSION}

The results of the evaluation were obtained from data on the panelist judgment on CocosGarri and ordinary garri due to sensory evaluation on the parameters considered. Also, the methodology and technology adopted in the production of the CocosGarri in this study had implication based on the panelist preference.

Appearance of CocosGarri showed no significant difference compared to ordinary garri in Fig. 2 at 0.05 confidence level of probability. This was considered as a good quality in term of acceptance of CocosGarri, because it will not be strange to consumers when compared to what they are normally used to. Fig. 2 also showed that despite no significant difference of appearance of both products, CocosGarri was highly acceptable by the panelists probably due to its fine colour and size as a result of the extra time spent on re-heating the garri, after being mixed with the homogenous mixture, this was similar to the report by Oduro et al, 2000 and Sanni et al, 2007.

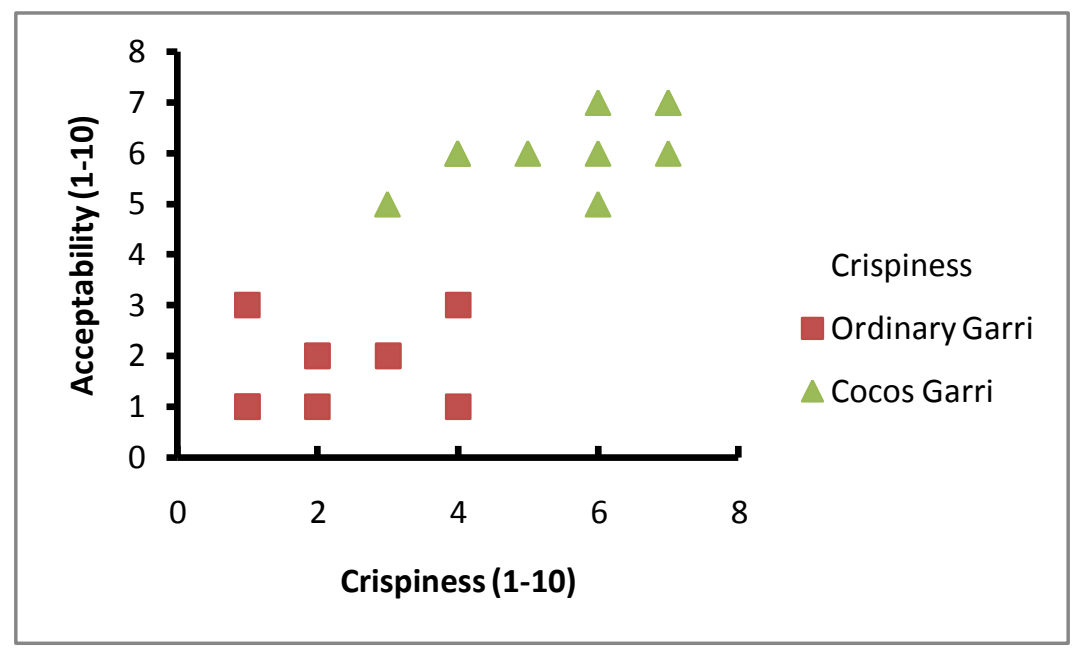

Fig.2. Graph showing that there was no significant difference in the appearance of CocosGarri and ordinary garri 
The result on Fig 3 showed that there was significant difference at 0.05 probability level on crispiness of CocosGarri and ordinary garri with $\mathrm{R}^{2}=0.6841$. This would be attributed to the second frying of the CocosGarri which made it crispier than the normal garri. This conforms to the report by Burubai and Etekpe, 2014 in terms of garri texture and particle size.

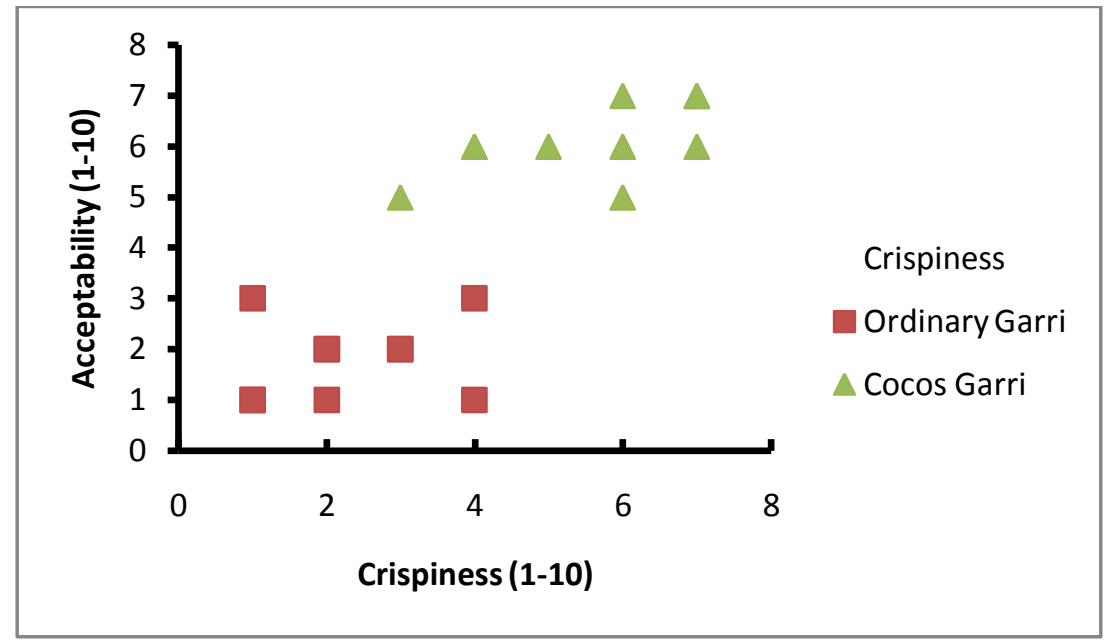

Fig 3. Graph showing the preference of crispiness of CocosGarri to ordinary garri

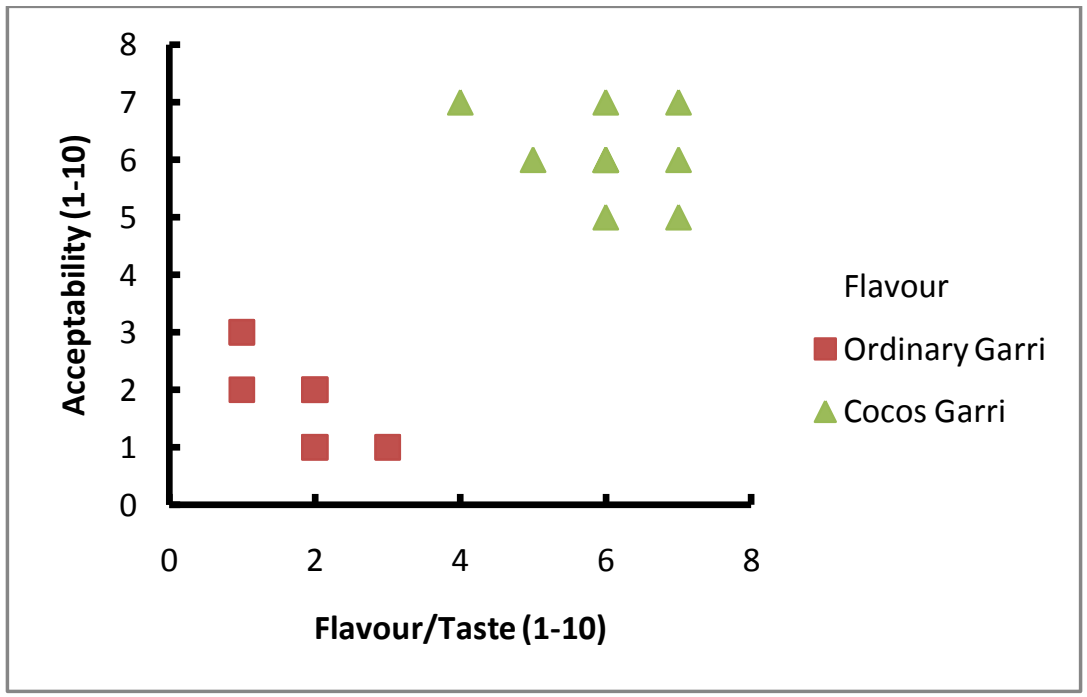

Fig 4. Graph showing the preference of flavour/taste of CocosGarri to ordinary garri

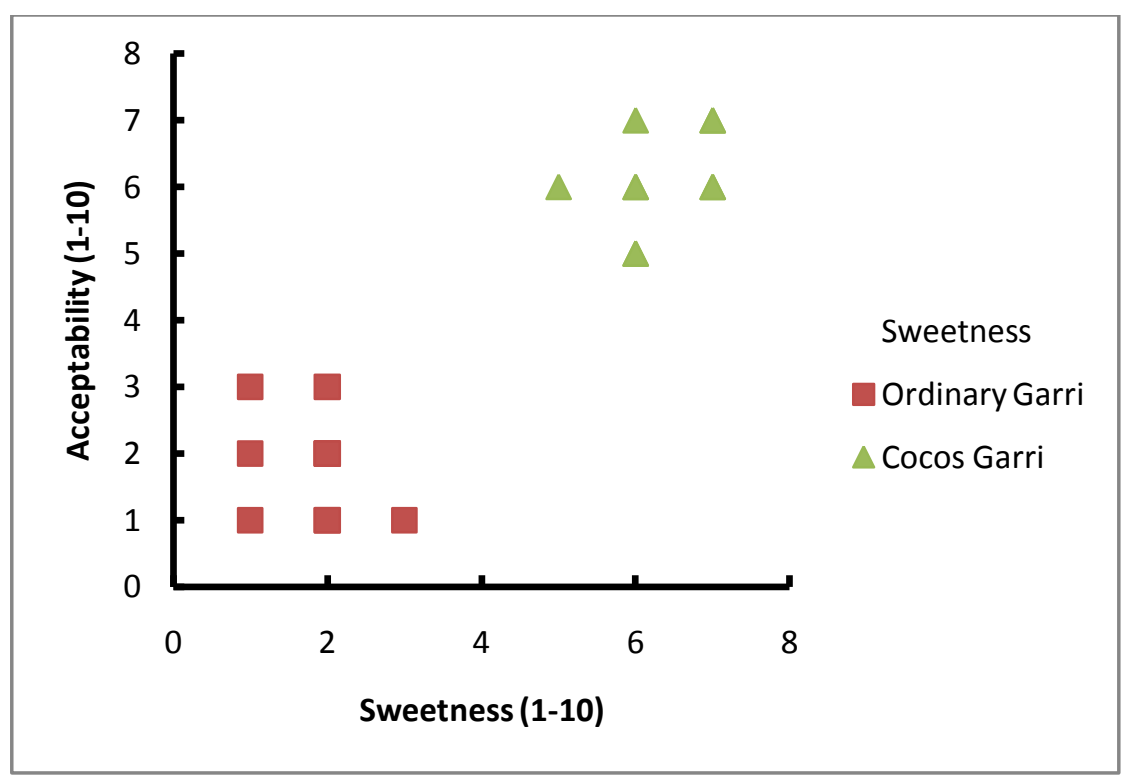

Fig 5. Graph showing the preference of sweetness of CocosGarri to ordinary garri 


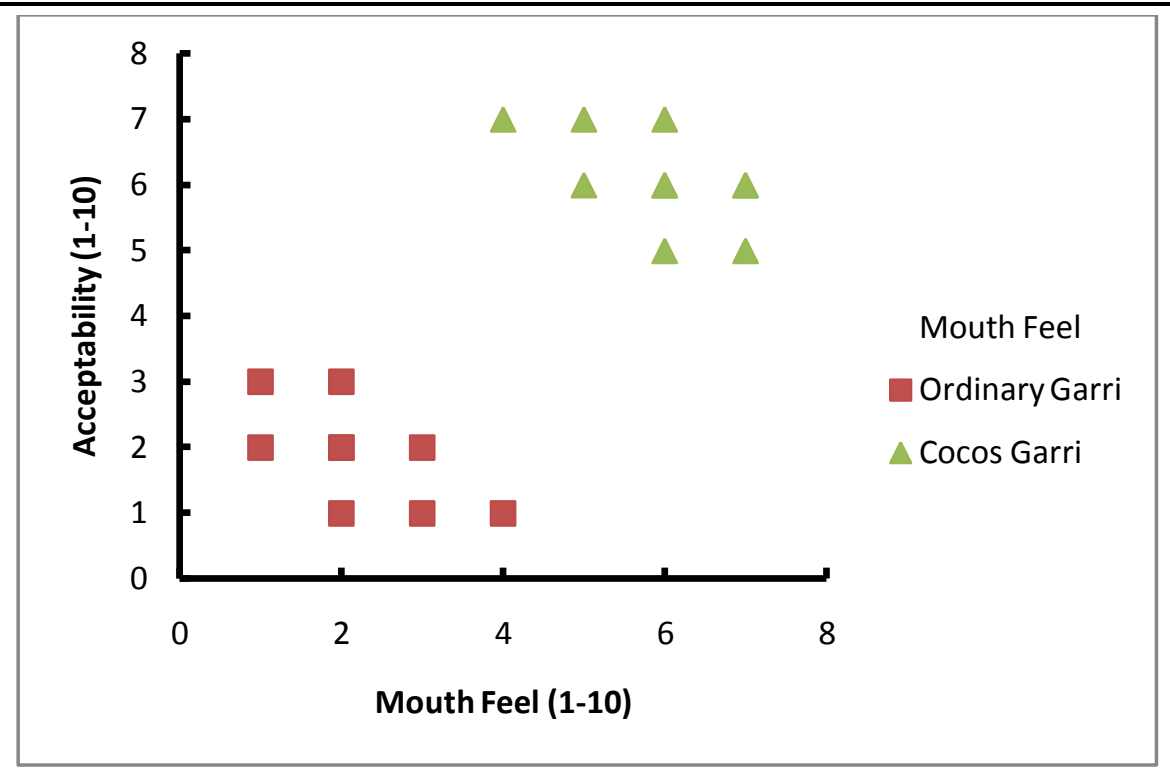

Fig 6. Graph showing the preference of mouthfeel of CocosGarri to ordinary garri

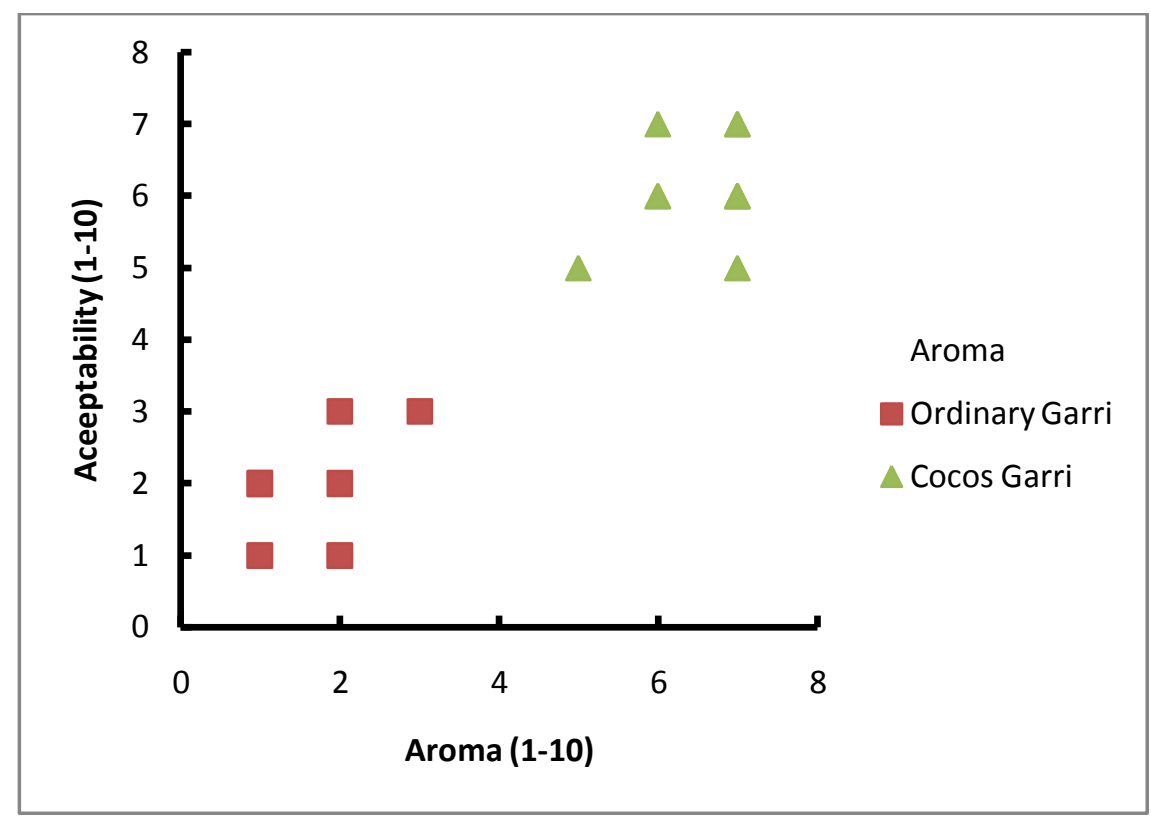

Fig 7. Graph showing the preference of aroma of CocosGarri to ordinary garri

Fig 4, presented the result of flavor and taste. Showed that there was significant difference at 0.05 level of probability between CocosGarri and ordinary garri with $\mathrm{R}^{2}=0.6717$. This would be attributed to the addition of the homogenous mixture in producing the CocosGarri which made it tastier and sweeter with a high acceptability score by the panelists. This was similar to the report by Oluwamukomi, 2015 in terms of enrichment of ordinary garri to improve its flavor and taste.

There was significant difference in CocosGarri over ordinary garri at 0.05 probability level on sweetness, with $\mathrm{R}^{2}=0.8397$, as showed in Fig 5 . This also made the acceptability score of CocosGarri to be higher compared to ordinary garri. This could be attributed to the addition of the homogenous solution in producing the CocosGarri which made it taste sweeter, as described by Oluwamukomi, 2015.

Fig 6 showed the result of mouth feel. It shows that there was significant difference at 0.05 probability between CocosGarri and ordinary garri with $\mathrm{R}^{2}=0.5936$. CocosGarri was highly acceptable by the panelists probably due to the extra time it spent on heating after it was immersed into the homogenous solution, this was as reported by Akerele et al., 1967.

Fig 7 also showed result of aroma. There was significant difference on CocosGarri over ordinary garri at 0.05 probability, with $\mathrm{R}^{2}=0.8958$. CocosGarri was highly acceptable by the panelists probably due to vanilla flavour added to the mix, as reported by Akerele et al., 1967. 


\section{CONCLUSION AND RECOMMENDATION}

The sensory and comparative analysis of ordinary garri and CocosGarri (Nutritionally enriched), showed that CocosGarri felt better in the mouth than ordinary garri when chewed. Also after the panelists' judgment, the extra products were sold and demand was high. This speaks generally on the consumer satisfaction and preference of CocosGarri over ordinary garri here in Nigeria. This therefore tells us that CocosGarri can be recommended for mass production because of its overall acceptability and long shelf life (6months and beyond) as tested. It can be introduced to other West African countries due to its high level of customer satisfaction and nutritional benefits. However, further research needs to be done to evaluate the nutritional composition for recommended dietary allowance and also to deduce its suitability for consumption by all groups. Evaluation on its shelf life also needs to be done in order to ascertain its specific expiration date and also evaluate the health challenges that can arise on consumption of expired product.

\section{REFERENCES}

[1] Akerele, I.A. (1967). Nutrient Enrichment of Garri. West African Journal of Biological and Applied Chemistry, 10: 19-22.

[2] Burubai, W. and Etekpe, G. W. (2014). Particle Size Characterization of Garri Powder. Advanced of Agricultural Research Vol. 2(12), pp. 197-202.

[3] Food and Agriculture Organization of the United Nations, (2004). The global cassava development strategy and implementation plan. Proceedings of the validation forum on the globalcassavadevelopmentstrategy, 1.RetrievedMarch14,2005, fromhttp://www.fao.org/document s/show_cdr.asp?url_file= / docrep/006/y0169e/y0169e00.htm.

[4] Hahn, S.K, and J. Keyser. (1985). Cassava: a basic food of Africa. Outlook on Agriculture 4: 95100.

[5] Hahn S. K. (1989). An overview of African traditional cassava processing utilization. Outlook on Agriculture, 1989; 18(3): 110- 118.

[6] Hahn, S.K., N.M. Mahungu, J.A Otoo, M.A M. Msabaha, N.B. Lutaladio, and M.T. Dahniya. (1987). Cassava end African food crisis. Pages 24-29 in Tropical root crops -root crops and the African food crisis. Proceedings, Third Triennial Symposium of the International Society for tropical Root Crops - Africa Branch, edited by E.R Terry, M. Akoroda, and O. B. Arene, 17-23 August 1986, Owerri, Nigeria.

[7] ISO 6564. (1985) Sensory analysis - Methodology - Flavour profile methods, International Organization for Standardization, Geneva (http://www.iso.org).

[8] Lewis, Michael John and Heppell, Neil. (2000) "Continuous Thermal Processing of Foods: Pasteurization and UHT Sterilization." Springer.

[9] Oduro, I., Ellis, W. O., Dziedzoave, N. T and Nimakoyeboah, K. (2000). Quality of Gari of Dried Cassava Chips into Garri. Nigeria Food Journal, 22, 65-73.

[10] Odunfa, S.A. (1998). Cassava to Gari. Nigerian Journal of Science and Technology.1:186 -189.

[11] Okafor, N. (1992). Commercialization of fermented foods in Sub-Saharan Africa. In Application of bacteriology to Traditional Ferment Foods, National Academic Press, USA. Official and Tentative methods of the American Oil Chemical Society I, AOCS, Champaign IL (1979).

[12] Oluwamukomi, M. O. (2015). Chemical and Sensory Properties of Gari enriched with Sesame seed flour (Sesamum Indicum L.). FUTA Journal of Research in Sciences, 2015 (1): 123-131.

[13] Oyewole, O. B. (1991). Fermentation of Cassava for Lafun Production. Food Lab. News 17(2):29-31.

[14] Sanni L.O., Babajide J.M. And Ojerinde M.W (2007). Effect of Chemical Pretreatments on the Physico-Chemical and Sensory Attributes Of Sweet Potato-Gari. An International Journal ASSET Series B 6 (1): 41-4936.

[15] World Health Organization and Food and Agriculture Organization of the United Nations Guidelines on food fortification with micronutrients. (2006) [cited on 2011 Oct 30].Micronutrient Fortification of Food: Technology and Quality Control.

[16] World Health Organization and Food and Agriculture Organization of the United Nations Guidelines on food fortification with micronutrients. (2006) [cited on 2011 Oct 30]. 